\title{
Closed Incision Management with Negative Pressure Therapy after Lower Limb Amputation in Vascular Imparaired Patients: our Initial Experience
}

\author{
Schoonjans C* \\ Department of Vascular Surgery, Belgium
}

*Corresponding author: Schoonjans C, Department of Vascular Surgery, Belgium

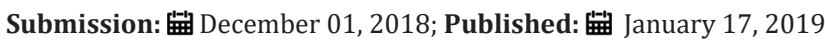

\section{Introduction}

Postoperative delayed wound healing, surgical site infections and other wound complications are associated with increased morbidity and health-care costs. In vascular surgery, wound complications can have serious consequences. Favorable results have been reported using closed incision negative pressure therapy (ciNPT) over various incision types. Studies have shown that ciNPT helps hold incision edges together, removes fluid and infectious materials, and protects incisions form external contamination. We report our initial experiences using a ciNPT over clean, closed lower limb amputation wounds.

\section{Methods}

A retrospective record review identified 4 patients ( 2 females, 2 males) where ciNPT was used following lower limb amputations for end-stage vascular disease between January 2016 and July 2017. All postamputation incisions were closed in layers with our standard technique and managed with ciNPT, which was applied in the sterile field of the operating room. ciNPT consisted of a self-adhesive foam dressing and a portable therapy unit (PREVENA Dressing, KCI, an Acelity company, Texas). The therapy unit provided continuous $-125 \mathrm{mmHg}$. No surgical drains were used with ciNPT [1,2].

\section{Results}

\section{Case series}

Patients had an average age of 78.5 \pm 9.85 years (range: 6791 years). All patients had end-stage peripheral vascular disease. Patient comorbidities included obesity, hypertension, active tobacco use and/or diabetes mellitus. Patients underwent an infragenual or transgenual amputation. ciNPT was left in place for 7 days. 3 incisions healed without complications, 1 was revised for local necrosis.

\section{Literature}

The vascular surgery population is at an increased risk of surgical site infections related to peripheral vascular disease, diabetes, obesity, previous surgery and presence of tissue loss. Negative pressure wound therapy dressings have been used on primarily closed incisions to reduce surgical site infections in other surgical disciplines. The mode of action of NPT on a closed surgical incision is notably different from the mode of action in open wounds. The combined effects of reduced lateral tension, improved lymphatic clearance, and reduction in hematoma and seroma may contribute to faster and stronger healing with reduced risk of infection and dehiscence (Figure 1).

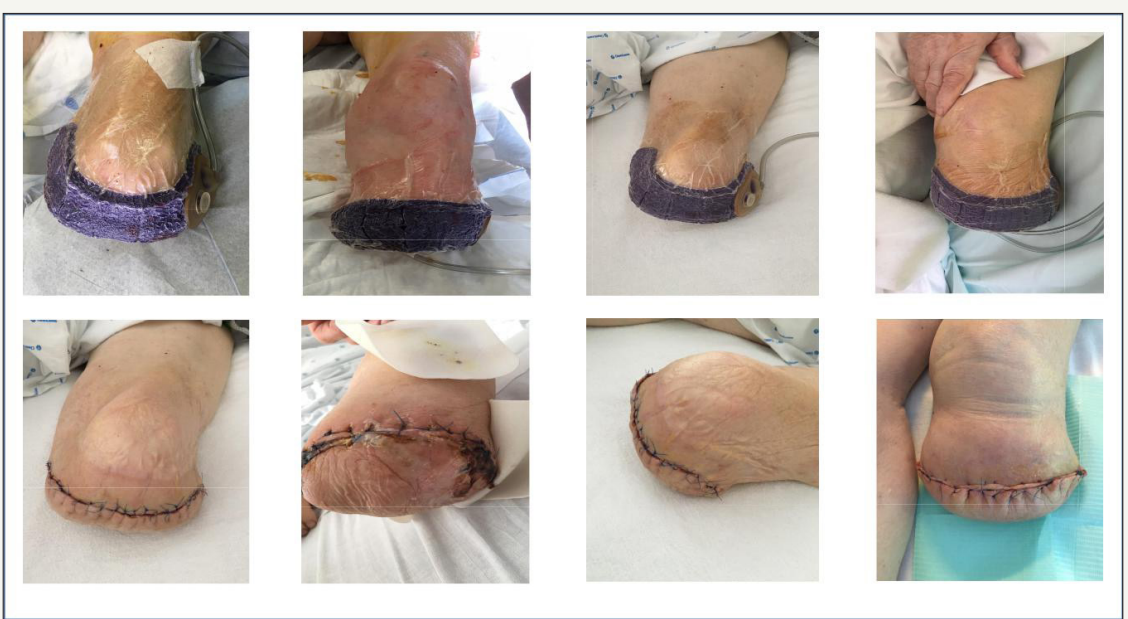

Figure 1: above - with ciNPT at day 0 (postoperatively) down - at day 7 when ciNPT was removed. 


\section{Conclusion}

ciNPT could be a viable option over closed incisions after lower limb amputations in vascular impaired patients at risk for postoperative wound complications.

\section{References}

1. Murphy P, Lee K, Dubois L, DeRose G, Forbes T, et al. (2015) Negative pressure wound therapy for high-risk wounds in lower extremity revascularization: study protocol for a randomized controlled trial. Trials 16: 504.
2. Strugala V, Martin R (2017) Meta-Analysis of comparative trials evaluating a prophylactic single-use negative pressurewound therapy system for the prevention of surgical site complications. Surg Infect 18(7): 810-819.

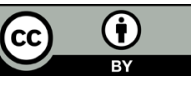

Creative Commons Attribution 4.0 International License

For possible submissions Click Here

Submit Article

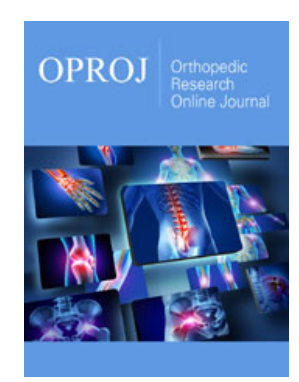

Orthopedic Research Online Journal

Benefits of Publishing with us

- High-level peer review and editorial services

- Freely accessible online immediately upon publication

- Authors retain the copyright to their work

- Licensing it under a Creative Commons license

- Visibility through different online platforms 